\title{
O património linguístico angolano na educação formal no namibe: desafios para o ensino superior
}

\section{Angolan Linguistic Heritage In Formal Education In Namibe: Challenges For Higher Education}

DOI: $10.46932 / \mathrm{sfjdv} 2 \mathrm{n} 2-159$

Received in: March 1st, 2021

Accepted in: May 30th, 2021

Teresa de Jesus Portelinha Almeida Patatas

Pós-doutoranda em Educação Comparada. Doutorada em Ciências da Educação pela Universidade Lusófona, Lisboa - Portugal.

Professora Auxiliar da Universidade do Namibe. Investigadora Associada do Centro de Estudos

Interdisciplinar de Educação e Desenvolvimento (CeiED).

Current Institution: Universidade do Namibe - Angola.

Address: Universidade do Namibe, Farol da Noronha, Moçâmedes, Namibe, Angola.

E-mail: teresapatatas.angola@gmail.com

Sebastião Tumitangua

Doutorado em Ensino das Ciências - Opção Biologia, pela Universidade de Ciências Pedagógicas Enrique José Varona, Cuba.

Professor Associado da Universidade do Namibe - Angola.

Current Institution: Universidade do Namibe.

Address: Universidade do Namibe, Moçâmedes, Namibe, Angola.

E-mail: tumi65@gmail.com

\section{RESUMO}

Uma língua é um instrumento de poder. Portanto, as línguas selecionadas nas políticas educativas regulam os contextos socioculturais. Uma pesquisa bibliográfica revela que, apesar da diversidade linguística angolana, a língua portuguesa foi preeminente na educação formal ao longo da história, passando de língua subjugação cultural e de expansão colonial, para ser a língua oficial depois da independência, prosseguindo como a língua de ensino. $\mathrm{Na}$ época colonial as línguas angolanas foram banidas da educação formal. Após a independência, passaram a ser consideradas como um importante património cultural e histórico, e, começaram a ser incorporadas no sistema educativo. Cada província angolana enfrentou este desafio. Esta comunicação tem como objectivo mostrar que a integração das línguas na educação formal é uma forma de valorização do património linguístico, focando o caso do Namibe. Nesta província este ensino expandiu-se do Primário para o Médio. Foram inquiridos: o Diretor Provincial de Educação, o Coordenador das Línguas Nacionais do Namibe e formador provincial, Diretores de três escolas e seus estudantes (de três turmas diferentes), onde as línguas nacionais são ensinadas. Os resultados mostram que o ensino das línguas angolanas é considerado fundamental para a valorização do património linguístico. Surge o desafio para o aumento interventivo do Ensino Superior nesta área, e para a sua extensão. Acredita-se que a expansão do ensino das línguas angolanas pode resultar numa maior valorização deste património linguístico, que se deseja preservar, transmitir e divulgar.

Palavras-chave: Património linguístico, Educação formal, Língua portuguesa, Línguas angolanas. 


\begin{abstract}
A language is an instrument of power. Therefore, the languages selected in education policies regulate the sociocultural contexts. Bibliographical research reveals that, despite the Angolan linguistic diversity, the Portuguese language was preeminent in formal education throughout history, beginning as a language of cultural subjugation and colonial expansion, to becoming the official language after independence, then continuing as the language of instruction. During the colonial period, Angolan languages were banished from formal education. After the independence, they started to be considered important to the cultural and historical heritage and began to be incorporated in the educational system. Each Angolan province faced this challenge. This communication aims to show that the integration of languages in formal education is a form of valorisation of the linguistic heritage, while focusing on the Namibe case. In this province, it has expanded from Primary to Secondary education. The following were interviewed: Provincial Director of Education, Coordinator of the National Languages of Namibe and provincial instructor, Directors from three schools and their students (of three different classes), from where the national languages are taught. The results show that teaching Angolan languages is considered crucial to the valorisation of the linguistic heritage. From this, the challenge arises for further intervention by Higher Education in this area and for its expansion. It is believed that expanding the teaching Angolan languages may result in a greater valorisation of this linguistic heritage, which one wishes to safeguard, pass on, and divulge.
\end{abstract}

Keywords: Linguistic heritage, Formal education, Portuguese language, Angolan languages.

\title{
1 NOTA INTRODUTÓRIA
}

As línguas selecionadas nas políticas educativas regulam os contextos socioculturais. Uma pesquisa bibliográfica revela que, em Angola, as políticas educativas, desde a colonização, determinaram a língua portuguesa como a língua de ensino. Após a independência, e sobretudo depois da paz, as línguas angolanas foram ganhando importância como património linguístico e cultural e gradualmente incluídas no sistema educativo, donde tinham sido banidas. Esta comunicação tem como objectivo mostrar que a integração das línguas na educação formal é uma forma de valorização do património linguístico, focando o caso da província do Namibe. Com este alvo, realizou-se uma pesquisa documental e para a recolha de dados empíricos foram entrevistados: o Diretor Provincial de Educação, o Coordenador das Línguas Nacionais do Namibe e formador provincial, Diretores de três escolas, onde as línguas nacionais são ensinadas; e, efetuaram-se grupos focais com os seus estudantes (de três turmas diferentes).

\section{HISTÓRICO}

Proferir acerca das línguas em Angola na época pré-colonial é uma tarefa árdua, pois as línguas eram ensinadas oralmente num contexto informal, e, para além disso, os portugueses deixaram poucos registos da história do povo Bantu dessa época (James, 2004, p. xl).

A língua não tem só uma função comunicativa, "ela pode ser vista como língua de prestígio, língua de expansão, língua de subjugação cultural ou língua de unidade nacional, em função do interesse político em fixar a norma.” (Quintas, Brás \& Gonçalves, 2017, p. 140). 
Pela pesquisa bibliográfica pode-se observar que, apesar da diversidade linguística angolana, mais de 60 línguas autóctones, a língua portuguesa foi preeminente na educação formal ao longo da história, passando de língua subjugação cultural e de expansão colonial, para ser a língua oficial depois da independência. Pois, segundo a Constituição da República (2010), Artigo 10, "a língua oficial da República de Angola é o português” (p.11). Prosseguindo como a língua de ensino, porquanto, de acordo com a Lei 17/16, de 7 de Outubro, Artigo 16º, alínea 1: “o Ensino deve ser ministrado em português.” (p. 3995).

$\mathrm{Na}$ época colonial as línguas angolanas foram relegadas da educação formal. Vilela (2001) refere que no Decreto $\mathrm{n}^{\mathrm{o}} 77$ do alto-comissário em Angola na época, Nórton de Matos, é exposto: «Art. ${ }^{\circ}{ }^{\circ}$ não é permitido ensinar nas escolas das missões línguas indígenas; Art. ${ }^{\circ} 3^{\circ}$ o uso da língua indígena só é permitida em linguagem falada na catequese e, como auxiliar, no período do ensino da língua portuguesa.» (p. 33). Decorrendo sobre este campo, Moutinho (2000) elucida que o colono considerava as línguas nativas como "simples dialetos, formas de comunicação rudimentares, em oposição à língua [portuguesa] que seria uma forma superior" (p. 72).

Após a independência, estas línguas (nativas) passaram a ser consideradas como um importante património cultural e histórico. No entanto, a transmissão deste património de modo vertical, isto é, dos elementos mais velhos para os elementos mais novos, encontrou dificuldades:

(1) A transmissão oral de valores culturais angolanos ficou um tanto comprometida pela deslocação das populações para os centros urbanos. Neste contexto, Fernando salienta que "o êxodo da população rural - celeiro da cultura - para os centros urbanos, mais seguros e com melhores condições, pode contribuir para esvaziar da 'alma' cultural dos povos e, deste modo, comportar irreparáveis consequências para a cultura angolana.” (p. 25).

Para Ferreira (2005), o êxodo rural para as cidades ampliou o número de indivíduos excluídos da educação formal. Isto porque, para os provenientes das zonas rurais a educação formal é culturalmente estranha, porque, nessa, as raízes e tradições africanas são subvalorizadas ou desconhecidas. Coloca-se, ainda, a questão linguística, os migrantes rurais têm de aprender e utilizar a língua portuguesa, como componente de integração na educação, no meio urbano e no mercado de trabalho, língua que lhe é culturalmente estranha.

(2) A transmissão escrita foi muito insípida. Fernando (2012) esclarece que "a guerra fratricida que devastou o País durante vinte e sete anos, mais outros catorze relativos à guerra anticolonial, dificultou deveras a recolha e posterior impressão dos aspetos culturais angolanos." (p. 24).

A escola, como agente educador, após a paz nacional, passou a intervir mais na valorização do património linguístico, começando a incorporar as línguas angolanas no sistema educativo. O ensino 
destas línguas começou em 2008. Na Constituição da República (2010), Artigo 19º refere que “o Estado valoriza e promove o estudo, o ensino e a utilização das demais línguas de Angola" (p. 11). Suplementarmente, segundo a Lei 17/16, de 7 de outubro, Artigo 16º alínea 2, “o Estado promove e assegura as condições humanas, cientifico-técnicas, materiais e financeiras para a expansão e generalização da utilização no ensino, das demais línguas de Angola” (id.).

Para Vilela (2001) o ensino de uma língua é essencial, porque, estimula a produção da literatura, assim como a investigação e ajuda na sua divulgação, pois contribui para que a língua seja conhecida fora das fronteiras do país de origem. Cada província angolana enfrentou este desafio do ensino das línguas angolanas e pautou o seu percurso.

\section{NAMIBE}

A província do Namibe encontra-se no litoral sul do País. Segundo o Censo de 2014 a sua População com mais de 2 anos de idade era constituída por 310.941 indivíduos (67,9\%), dividida entre a Urbana $(257.719$ pessoas $=87,9 \%)$ e a Rural $(53.222$ pessoas $=32,3 \%)$.

\subsection{LÍNGUAS NA PROVÍNCIA}

Quanto às línguas "o português é falado por mais de metade da população (68\%) com maior predominância nas áreas urbanas, onde $88 \%$ da população fala a língua portuguesa, contra somente $32 \%$ na área rural" (Instituto Nacional de Estatística-INE, 2016, p. 38). Depois do português "o umbundo é a segunda língua mais falada com 20\%, seguindo-se as línguas Nyaneca e Muhumbi com 12\% e 11\% respetivamente.” (INE, 2016, p. 38). As outras línguas usadas nesta região são: Côkwe, Kwanyama, Fiote, Kikongo, Kimbundu, Nganguela, e, Luvale.

A província é constituída por 5 municípios: Kamucuio, Bibala, Virei, Tômbua (ou Tômbwa) e Moçâmedes (município sede, anteriormente denominado Namibe), a Figura 1 apresenta a distribuição das línguas nos municípios: 
Figura 1 - Principais línguas mais faladas por província, 2014

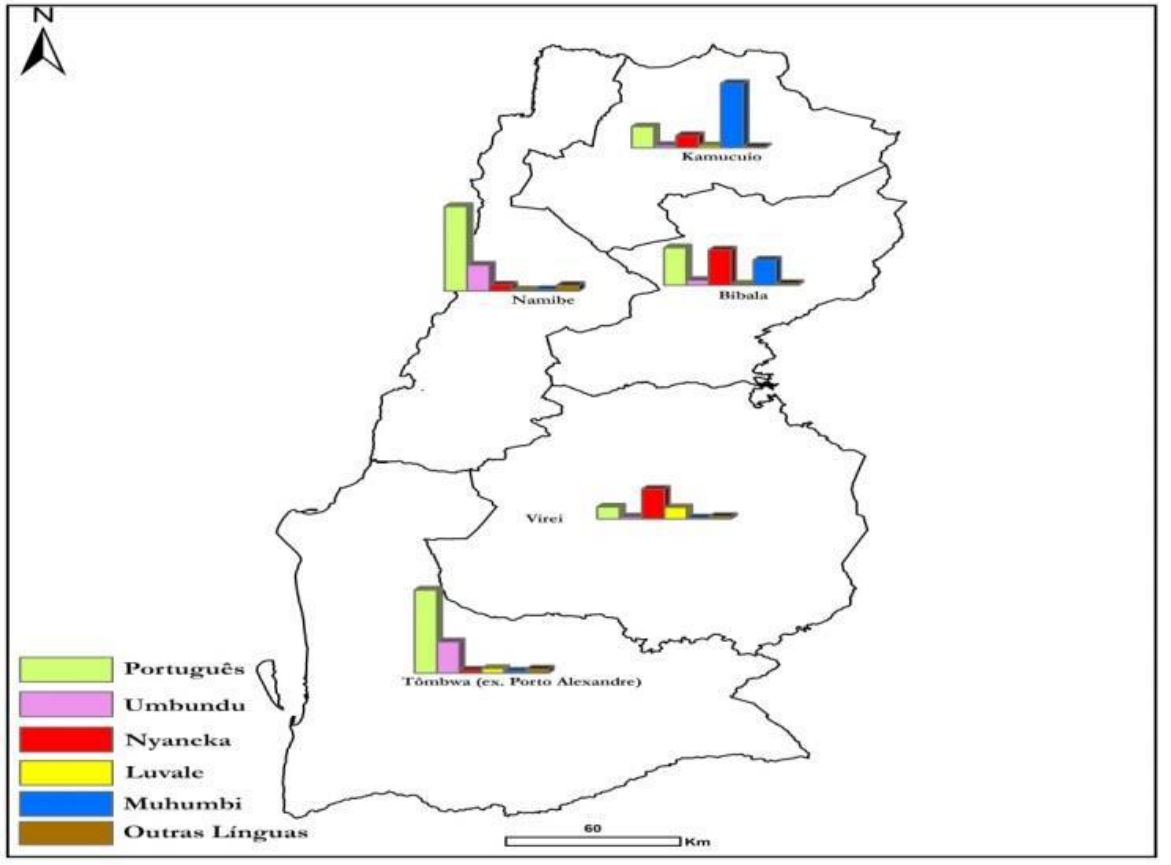

Fonte: INE (2016, p. 38)

\subsection{ENSINO DAS LÍNGUAS}

O ensino das línguas angolanas a nível nacional começou em 2008, conforme referido, contudo, por diversas razões, na província do Namibe apenas se iniciou em 2012, depois de uma formação para professores na área, em 2011. Nos municípios a introdução do ensino das línguas angolanas não foi sincrónica, como se verá, mas, o ensino expandiu-se do Primário ao Médio. Uma pesquisa documental, autorizada pelo departamento provincial da área, revela esta evolução, segundo os dados que se seguem:

O ensino principiou em três municípios: Namibe (atual Moçâmedes), Bibala e Kamucuio, com 26 professores e 1305 alunos e somente no Ensino Primário. Em 2014 iniciou no município do Tômbua. Em 2015, o ensino é estendido ao Ensino Médio nos primeiros três municípios. No município do Virei o ensino das línguas inaugurou-se apenas em 2017.

Os dados estatísticos desse ano (2017) indicam uma expansão deste ensino a nível provincial, com a presença do ensino das línguas em todos os municípios, e, um número crescente de seus alunos, totalizando 12.990 no Ensino Primário e 1.148 no Ensino Médio, lecionados por 175 professores formados para essa finalidade.

Nesta província, apesar da referida diversidade linguística, foram escolhidas apenas duas línguas para o ensino: (1) Nyaneka (ou Olunyaneka), e (2) Umbundo. O Responsável pelo Gabinete das Línguas de Angola no Namibe ${ }^{1}$ esclarece esta seleção:

\footnotetext{
${ }^{1}$ César Joaquim, numa entrevista em Março de 2018.
} 
“(1) Nyaneka por ser a primeira língua ou segunda mais falada na província, especialmente no município sede (Moçâmedes). O povo endógeno, os Mucubais, tem um legado de nunca trabalhar ou partilhar a vida com outros povos (falam Mucubal) e vivem em zonas rurais em comunidades isoladas. Assim, para obter a mão-de-obra para a economia local, esta teve de ser importada da província vizinha (Huíla), onde se fala maioritariamente Olunyaneka e esta comunidade acabou por se estabelecer no Namibe. O (2) Umbundo, por ser a língua nacional mais falada em todo o território, rondando $40 \%$ da população.”

A escola elege a língua a ser ensinada consoante a formação dos professores indicados para essa função, neste caso a língua não é opcional; porém, se houver professores para as duas línguas, os alunos podem escolher e geralmente optam por aquela que é falada pelos familiares.

\subsection{IMPORTÂNCIA DO ENSINO DAS LÍNGUAS}

O Diretor Provincial de Educação salientou a importância do ensino das línguas angolanas, nomeadamente: no combate ao analfabetismo; permite uma comunicação mais lacta entre as comunidades; no apoio ao combate à pobreza; e, nas campanhas de sensibilização, por exemplo vacinação e informação sobre doenças; assim como na manutenção da paz.

Nesse âmbito, o Coordenador das Línguas Nacionais do Namibe e formador provincial, salientou que "as línguas são portas do conhecimento e do saber, cria atitudes, competências e inovação, para abrir as consciências e para o autorreconhecimento."

Para conhecer melhor esta realidade foram inquiridos os Diretores de três escolas e seus estudantes (de três turmas diferentes), onde as línguas nacionais são ensinadas: Instituto das Ciências Religiosas de Angola (ICRA); Escola de Magistério Primário Nº78 - Júlia Lopes; Escola do Ensino Primário N²4N Kumangala. Estas escolas foram selecionadas pela sua particularidade: o ICRA por ser um instituto com sustentáculo religioso; o Magistério Primário por formar professores; e, uma escola primária pública para, assim, abranger-se os vários níveis de ensino neste estudo. Também, por dificuldades de deslocação e calendarização, focou-se apenas nestas escolas do município-sede (Moçâmedes).

Aos diferentes diretores também foi questionado sobre a importância de aprender e comunicar em línguas angolanas, eis as respostas mais significativas:

"Ensinar línguas é educar o povo, a língua é a riqueza do país, faz parte do mosaico cultural de um povo.” (Diretor do Instituto das Ciências Religiosas de Angola).

“A língua faz parte da identidade cultural de um povo e os angolanos perderam muitos desses fatores pela guerra e colonização. É importante sabermos da nossa cultura e identidade e aprofundar os conhecimentos interativos.” (Diretora da Escola de Magistério Primário No 78).

"As línguas nacionais têm muito da história de Angola, têm muita coisa que traduz a nossa realidade, tradições, valores e raciocínios que não aparecem na língua portuguesa. Aprender as línguas é repor alguns elementos perdidos durante a colonização quando era proibido usar essas línguas." 
Adicionou também que "a língua é um bem público. As línguas nacionais são bens do Estado, uma riqueza, um valor que o País tem que tem de ser preservado, valorizado e protegido pelo Estado.” (Diretor da Escola do Ensino Primário N²4N Kumangala).

Para saber a perceção dos alunos, foram feitos grupos focais, em Abril de 2018, em turmas de diferentes classes, com distintas faixas etárias - afiançando que estes podem ser representativos de um universo por enquanto impreciso (pois o ano letivo de 2018 começou em Março e as estatísticas ainda não foram divulgadas) - conforme está na Tabela 1.

Tabela 1: Inquiridos no Município de Moçâmedes

\begin{tabular}{|c|c|c|c|c|c|}
\hline \multirow[b]{2}{*}{ ESCOLA } & \multirow[b]{2}{*}{ CLASSE } & \multirow{2}{*}{$\begin{array}{c}\text { FAIXA } \\
\text { ETÁRIA }\end{array}$} & \multicolumn{2}{|c|}{ GÉNERO } & \multirow{2}{*}{$\begin{array}{l}\text { TOTAL } \\
\text { DE } \\
\text { ALUNOS }\end{array}$} \\
\hline & & & M & $\mathrm{F}$ & \\
\hline Instituto das Ciências Religiosas de Angola (ICRA) & $13^{\mathrm{a}}$ & 18 a 28 anos & 14 & 18 & 32 \\
\hline Escola de Magistério Primário Nº78 - Júlia Lopes & $12^{\mathrm{a}}$ & 17 a 40 anos & 06 & 24 & 30 \\
\hline Escola do Ensino Primário N²4N Kumangala & $6^{\mathrm{a}}$ & 10 a 13 anos & 18 & 10 & 28 \\
\hline TOTAIS & - & - & 38 & 52 & 90 \\
\hline
\end{tabular}

Fonte: dados empíricos recolhidos.

Algumas das respostas consideradas mais pertinentes dadas pelos estudantes do género masculino: "Permite a identificação cultural de um determinado povo. Pois, um povo sem cultura é como um livro sem grafia e um livro sem grafia é como um livro sem tema (ditado popular) "; e, "O ensino das línguas é um meio de preservar a nossa cultura para a geração vindoura”.

Seguem-se também exemplos de respostas de estudantes do género feminino: "Quem não sabe da sua cultura é um vazio cultural, a falta de prática de uma língua é a falência de uma aprendizagem”; "Uma língua caracteriza uma cultura”; "A língua é um intercâmbio de comunicação cultura do nosso país“; e, "a língua ajuda a comunicar com os mais velhos, é um regresso às raízes e nossas culturas".

Os resultados mostram que a integração das línguas na educação formal é uma forma de valorização do património linguístico e o seu ensino é considerado fundamental para esse propósito.

Também foi inquirido sobre as vantagens de aprender e saber línguas angolanas, as respostas, tanto dos diretores e alunos foram coincidentes e resumidas nos seguintes itens:

Comunicação e interação com outros povos;

$\checkmark$ Redução de conflitos;

$\checkmark$ Resgate e valorização dos valores culturais;

$\checkmark$ Empatia e compreensão de situações culturais diferentes;

$\checkmark$ Destruição de barreiras étnicas;

$\checkmark$ Desenvolvem-se competências comunicativas;

$\checkmark$ Partilha de valores realmente angolanos; 
$\checkmark$ Permite a identificação e preservação cultural e nacional;

$\checkmark$ Interesse e valorização na variedade cultural angolana;

$\checkmark$ Regresso às origens, ao "nosso".

\section{Os Diretores salientaram:}

Facilitar e satisfazer o cliente no atendimento e uso dos serviços.

\section{Os alunos acresceram:}

Falar com os mais velhos ou com quem vive nas zonas onde não se fala português.

Como se pode ver existem várias vantagens vindas do ensino e aprendizagem das línguas angolanas.

\section{ENSINO SUPERIOR}

Surge o desafio para o aumento interventivo do Ensino Superior na área do ensino das línguas, e para a extensão desse ensino específico. Quando inquirido sobre este assunto, o Diretor Provincial de Educação, afirmou que, o Ensino Superior podia intervir mais:

$\checkmark$ Na investigação do património linguístico, com grupos interdisciplinares; e,

$\checkmark$ Na divulgação dessa investigação;

$\checkmark$ Dar formação profissional na área;

$\checkmark$ Formar quadros em linguística, tradução e didática das línguas angolanas; e,

$\checkmark$ Preparar professores para ensinar.

As respostas à mesma questão do Coordenador das Línguas Nacionais do Namibe e formador provincial, reforça a necessidade da formação de quadros na área realizada pelo Ensino Superior e de investigação linguística, nesse âmbito é importante focar no resgate do conhecimento dos mais velhos para melhor conhecimento do uso das línguas.

O Diretor acrescentou, respondendo à pergunta sobre «para quando a inserção das línguas angolanas no Ensino Superior?», que as línguas poderão ser integradas desde que haja professores para as ensinar a este nível de ensino.

\section{NOTA CONCLUSIVA}

Banidas do sistema educativo no tempo colonial, após a independência, sobretudo depois da paz, as línguas angolanas foram ganhando importância como património linguístico e cultural. Gradualmente, a partir de 2008, foram sendo integradas nas escolas, começando no Ensino primário. Esta comunicação 
teve como objectivo mostrar que essa integração (das línguas na educação formal) é uma forma de valorização do património linguístico, focando o caso da província do Namibe.

No Namibe, o ensino das línguas angolanas começou em 2012 e foram escolhidas as línguas: Nyaneka e Umbundo. Nos diferentes municípios, apesar de este ensino ter tido um início diferenciado, tem crescido o número de turmas e de escolas e também (este ensino) foi expandido para o Ensino Médio.

Os resultados empíricos, obtidos por entrevistas e grupos focais, confirmam que a integração das línguas na educação formal é definitivamente uma forma de valorização do património linguístico e este ensino é percecionado pelo Diretor Provincial, Coordenador das Línguas Nacionais do Namibe, Diretores de escolas e alunos, como fundamental para esse propósito. Também são consideradas várias vantagens para a aprendizagem e uso dessas línguas nos diferentes campos, sobretudo no sociocomunitário.

O Ensino Superior pode ser mais interventivo nesta área em diferentes e possíveis ações. Acreditase que a expansão do ensino das línguas angolanas, e uma intervenção crescente do Ensino Superior nesta área, pode resultar numa maior valorização deste património linguístico, que se deseja preservar, transmitir e divulgar. 


\section{REFERÊNCIAS BIBLIOGRÁFICAS}

Constituição da República. (2010). Luanda: Governo de Angola.

Fernando, B. (2012). A fauna e as finalidades didácticas em alguns provérbios Bacongo. Luanda: Instituto Nacional das Indústrias Culturais (INIC).

Ferreira, M. J. S. M. (2005). Educação e política em Angola, uma proposta de diferenciação social. Centro de Estudos Africanos/ISCTE.

Instituto Nacional de Estatística (INE). (2016) Censo 2014: Resultados definitivos: Recenseamento Geral da população e da habitação de Angola 2014 - Província do Namibe. Luanda: INE.

James, W. M. (2004). Historical Dictionary of Angola. Toronto: The scarecrow Press.

Lei 17/16, de 7 de Outubro, I Série - Nº 170.

Moutinho, M. (2000). O indígena no pensamento colonial português - 1835-1961. Lisboa: Edições Universitárias Lusófonas.

Quinta J., Brás, J. \& Gonçalves, M. N. (2017). O Umbundo no poliedro linguístico angolano. Revista Lusófona de Educação, 35, 137- 154.

Vilela, M. (2001). Reflexões sobre a política linguística nos PALOP. Africana Studia, 4, 2001, 33-48. 